\title{
Optimized Combinatorial Properties of an AIMgSi(Cu) Alloy Achieved by a Mechanical-Thermal Combinatorial Process
}

\author{
Li-Mei Liu ${ }^{1} \cdot$ Yu-Xiang Lai ${ }^{1} \cdot$ Chun-Hui Liu ${ }^{1}$ Jiang-Hua Chen ${ }^{1,2}$ \\ Received: 23 May 2018/Revised: 23 July 2018/Published online: 20 September 2018 \\ (C) The Chinese Society for Metals and Springer-Verlag GmbH Germany, part of Springer Nature 2018
}

\begin{abstract}
Enhancing combinatorial properties, such as excellent corrosion resistance, high strength and good ductility combined, is an important issue for manufacturing high-quality $\operatorname{AlMgSi}(\mathrm{Cu})$ alloys. Here, we show that this can be achieved by optimizing a combinatorial process consisting of pre-ageing, cold-rolling and post-ageing to tailor the hierarchical microstructures of the alloy. Transmission electron microscopy analysis reveals that the enhanced combinatorial properties of corrosion resistance, strength and ductility are owing to modification of grain boundary microstructure in good association with changes of precipitate microstructures and a more homogenous distribution of solute atoms, as compared with the microstructures of the alloy processed by thermal ageing only.
\end{abstract}

Keywords Al alloy $\cdot$ Corrosion resistance $\cdot$ Mechanical property $\cdot$ Ageing $\cdot$ Deformation

\section{Introduction}

Heat-treatable $\mathrm{Al}$ alloys with light weight have been widely used in transportation industry, such as high speed train, automotive and airplane [1-3]. Unfortunately, localized corrosion at the surface can lead to the rapid failure of $\mathrm{Al}$ alloys [4]. This is extremely adverse for automotive vehicles, marine ships and aircraft aimed for long-term safe service. Pure $\mathrm{Al}$ or dilute $\mathrm{Al}$ alloys such as $\mathrm{AlMgSi}$ alloys actually possess excellent corrosion resistance [4-6]. However, these alloys are faced with restricted use in some parts for which high strength is required. Al alloys are typical precipitation hardened metals; hence, strength promotion is mainly acquired by tuning the alloy chemistry content and ageing tempers to obtain abundant strengthening precipitates [7-12]. The high-strength Al alloys

Available online at http://link.springer.com/journal/40195

Jiang-Hua Chen

jhchen123@hnu.edu.cn

1 Center for High-Resolution Electron Microscopy, College of Materials Science \& Engineering, Hunan University, Changsha 410082, China

2 Hunan Province Key Laboratory for Spray Deposition Technology and Application, Hunan University, Changsha 410082, China contain relatively high concentration of alloying elements [9-15], particularly, $\mathrm{Cu}$ and $\mathrm{Zn}$, which have large electrochemical difference with $\mathrm{Al}[4,16,17]$. With increasing $\mathrm{Cu}$ content, the corrosion susceptibility would increase. Conventional thermal treatment (T6 temper) of $\mathrm{Al}$ alloy usually consists of solution treatment, quenching and subsequent ageing. The ageing treatment influences the microstructure by not only the solutes precipitation inside the matrix but also the diffusion of solutes towards the grain boundaries $[8,14]$.

The corrosion behaviours are sensitive to the microstructure heterogeneity such as second phases and grain boundary segregation (GBS) which can introduce microgalvanic couples with the matrix. Second-phase particles can cause pitting corrosion on itself or the matrix depending on the electrochemical potential and the type of reaction $[4-6,10,18]$. The microstructures of the grain boundaries in most peak-aged $\mathrm{Cu}$ and/or $\mathrm{Zn}$ containing $\mathrm{Al}$ alloys are characteristic of GBS and precipitate-free zone (PFZ) due to the depletion of solutes in the region near the grain boundary $[4-6,16,17,19,20]$. Owing to the electrochemical difference between GBS and PFZ, especially when the GBS is continuously distributed, this kind of microstructure is very vulnerable to the inter-granular corrosion (IGC) [20]. IGC is deleterious as it can penetrate deeply into the materials and induce the onset of catastrophic crack [4]. The IGC can be deteriorated by over- 
ageing while the strength would be reduced at the same time $[5,6]$.

The pioneering efforts to solve the dilemma of strength and corrosion resistance mainly include multi-step ageing [21-23] and ultra-refining of grain sizes [24-27]. The principles of multi-step ageing, including interrupted ageing and T78 (high-temperature ageing with foregoing relatively low temperature ageing) are to mitigate or discontinue the GBS while prohibiting the coarsening of matrix precipitates [21-23]. Nonetheless, the strength and corrosion resistance acquired by this method need further improvement. It has been reported [26, 27] that IGC susceptibility could be decreased by rearrangement of grain boundary in high-strength Al alloys processed by severe plastic deformation (SPD). These findings provide valuable insights into the relationship between grain size and corrosion resistance. However, the SPD processes are always difficult to perform and their applications are still limited. Recently, by a mechanical-thermal process consisting of pre-ageing, cold-rolling and post-ageing process, high strength, good ductility and high corrosion resistance could be obtained in $\mathrm{Al}$ alloys [28-33]. This process is more easily to be conducted than SPD process, and it can produce samples with large size. Besides, it results in higher strength and corrosion resistance than multi-step ageing.

In the present work, we propose an optimization of postageing treatment for producing highly corrosion resistant Al alloys with significantly enhanced strength and good ductility. Based on intelligent nanostructural design by combination of deformation and post-ageing, our method is capable of eliminating the IGC while restoring the strength from the crystal defects, lamella-like sub-grains and nanosized precipitates. In addition, the ductility is comparable with T6-treated alloy.

\section{Experimental}

An alloy with a chemical composition of $1.00 \mathrm{Mg}-0.50 \mathrm{Si}-$ $0.80 \mathrm{Cu}-0.14 \mathrm{Fe}-0.24 \mathrm{Cr}-0.02 \mathrm{Ti}-$ balance $\mathrm{Al}$ (wt\%) was used in this study. The initial materials were 5-mm-thick hot-rolled plates, and two different thermo-mechanical routes were then adopted to process the alloys. The plates were firstly solution treated at $560{ }^{\circ} \mathrm{C}$ for $30 \mathrm{~min}$ and water quenched immediately followed by pre-aged at $180{ }^{\circ} \mathrm{C}$ for $10 \mathrm{~min}$. Subsequently, the samples were cold-rolled through multiple steps to a sheet of $1 \mathrm{~mm}$ in thickness. Eventually, the as-rolled alloys were post-aged at $180^{\circ} \mathrm{C}$, $150{ }^{\circ} \mathrm{C}$ and $120^{\circ} \mathrm{C}$, respectively, in an oil bath. These samples are referred to as DA samples hereafter. As a comparison, typical conventional T6 tempers were also performed by changing the sequence of the above procedures. The thick plates were directly cold-rolled by the same rolling condition to 1 -mm-thick sheets. Then, the asrolled sheets were solution treated at $560{ }^{\circ} \mathrm{C}$ for $30 \mathrm{~min}$ followed by aged at $180{ }^{\circ} \mathrm{C}$. More details of the processing routes have been shown in the literature [28, 31]. The corrosion behaviour was investigated by conducting accelerated immersion tests in an aqueous chloride-peroxide solution according to ASTM G110 practice. Sheets were cut into slices of $10 \mathrm{~mm} \times 8 \mathrm{~mm} \times 1 \mathrm{~mm}$. The specimens were cleaned with ethanol after mechanical polishing. Using the ASTM G110 practice, the samples were etched for $1 \mathrm{~min}$ at $93{ }^{\circ} \mathrm{C}$ in a solution of $5 \mathrm{~mL}$ hydrofluoric acid ( $\mathrm{HF}, 48 \%)$ and $50 \mathrm{~mL}$ nitric acid $\left(\mathrm{HNO}_{3}\right.$, $70 \%$ ) per $\mathrm{L}$ of deionized water. Then, the samples were immersed for $24 \mathrm{~h}$ in a solution of $57 \mathrm{~g}$ sodium chloride $(\mathrm{NaCl})$ and $10 \mathrm{~mL}$ hydrogen peroxide $\left(\mathrm{H}_{2} \mathrm{O}_{2}, 30 \%\right)$ per $\mathrm{L}$ of deionized water at ambient temperature. Afterwards, the samples were washed in distilled water, rinsed in ethanol and finally dried in cold air. After polishing and ultrasonic cleaning to remove any additional corrosion products formed on the surface layers of the corroded samples, the cross-sectional microstructures were observed using a FEI Quanta 200 scanning electron microscopy (SEM). The tensile samples were machined according to the specification in ASTM Standard E 517-00 with the longitudinal axis parallel to the cold-rolling direction. Tensile tests were carried out at room temperature using an Instron 3369 universal machine operated at an initial quasi-static strain rate of $1 \times 10^{-3} \mathrm{~s}^{-1}$. The microstructures of the samples were characterized by a FEI Tecnai F20 transmission electron microscopy (TEM) operated at $200 \mathrm{kV}$. TEM thin foils were prepared by twin-jet electro-polishing with a solution of $30 \%$ nitric acid in methanol below $-25^{\circ} \mathrm{C}$ at an operating voltage of $15 \mathrm{~V}$.

\section{Results and Discussion}

Figure 1 shows the SEM cross-sectional micrographs of T6 aged samples. The results reveal a strong dependence of the corrosion with the ageing time. As shown in Fig. 1a, the under-aged (aged for $30 \mathrm{~min}$ ) sample actually already suffers the IGC attack with the maximum penetration depth of $133 \mu \mathrm{m}$. For the peak-aged sample (aged for $24 \mathrm{~h}$ ), there is a rather severe susceptibility to IGC. The maximum permeation depth can be as deep as $241 \mu \mathrm{m}$ (Fig. 1b). When the ageing treatment was prolonged to the later stage (aged for $120 \mathrm{~h}$ ) (Fig. 1c), the IGC is really diminished, as consistent with the literature $[5,6]$, with the maximum permeation depth of approximately $157 \mu \mathrm{m}$.

The morphologies of the cross sections in the corroded DA samples post-aged at $180{ }^{\circ} \mathrm{C}$ are shown in Fig. 2a-c. Compared to the T6 samples, it is striking that IGC depths decrease a lot during the immersion. After post-ageing for 

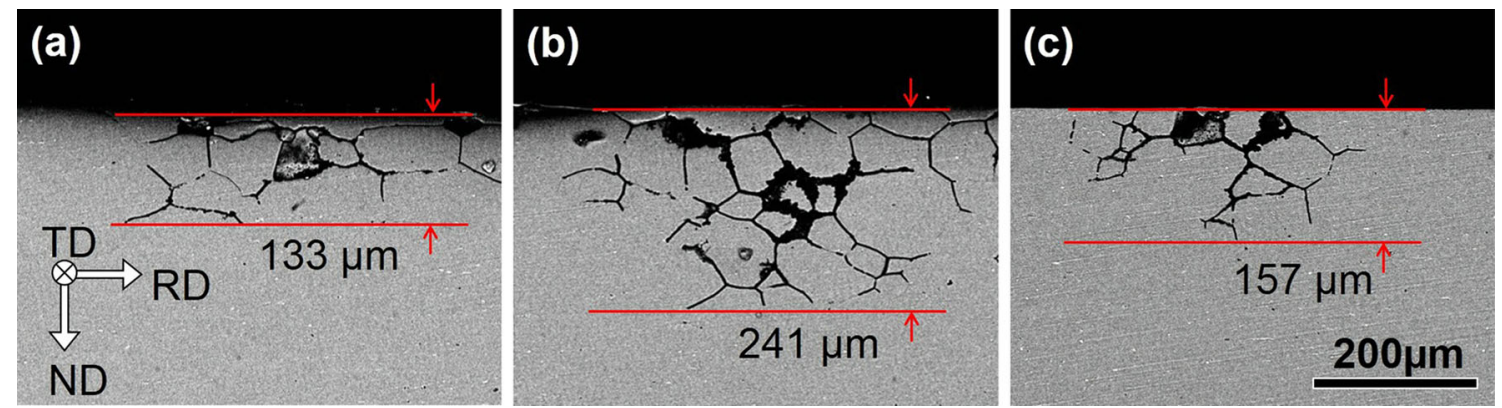

Fig. 1 SEM cross-sectional micrographs of the alloys T6 aged for a $30 \mathrm{~min}, \mathbf{b} 24 \mathrm{~h}, \mathbf{c} 120 \mathrm{~h}$. The observation plane is shown by the inset sketch
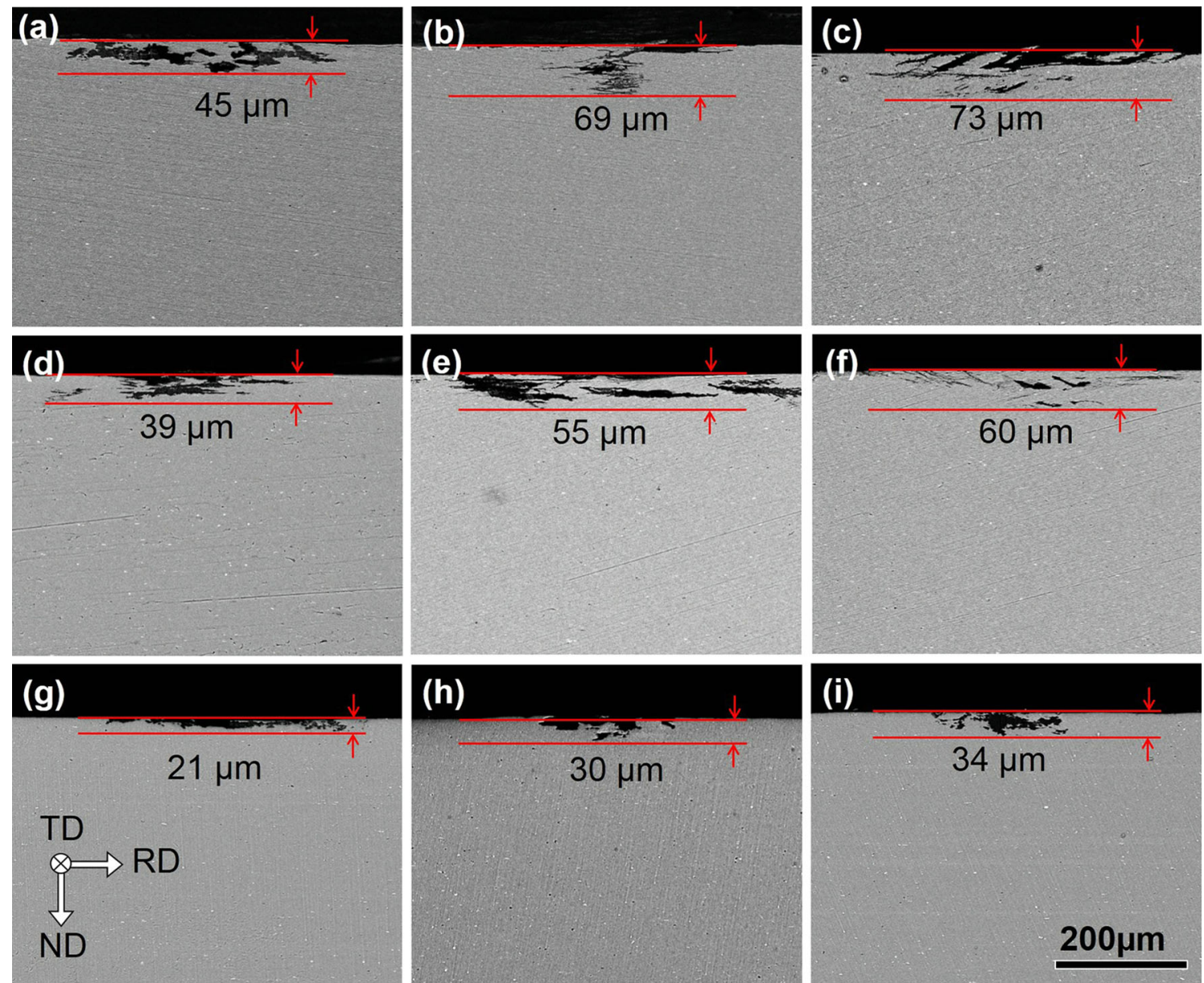

Fig. 2 DA alloys post-aged at $180{ }^{\circ} \mathrm{C}$ for a $10 \mathrm{~min}, \mathbf{b} 30 \mathrm{~min}, \mathbf{c} 48 \mathrm{~h}$; at $150{ }^{\circ} \mathrm{C}$ for $\mathbf{d ~} 30 \mathrm{~min}, \mathbf{e ~} 8 \mathrm{~h}, \mathbf{f} 144 \mathrm{~h}$; at $120{ }^{\circ} \mathrm{C}$ for $\mathbf{g} 1 \mathrm{~h}, \mathbf{h} 60 \mathrm{~h}, \mathbf{i} 120 \mathrm{~h}$ after immersion test. The observation plane is shown by the inset sketch

$10 \mathrm{~min}$, very shallow corrosion below the surface of the sample are observed (Fig. 2a). With the post-ageing time extending to $30 \mathrm{~min}$, the development of corrosion depth keeps limited (Fig. 2b). When the post-ageing time reaches $48 \mathrm{~h}$, the local corrosion depth increases a little bit (Fig. 2c). But the maximum corrosion depth (approximately $73 \mu \mathrm{m}$ ) is still very small relative to the depths of IGC in all the T6 samples. After post-under-ageing at $150{ }^{\circ} \mathrm{C}$ for $30 \mathrm{~min}$, post-peak-ageing for $8 \mathrm{~h}$ and post-over- ageing for $144 \mathrm{~h}$ (as shown in Fig. 2d-f, respectively), compared to those of the samples post-aged at $180{ }^{\circ} \mathrm{C}$, the corrosion depths of the alloys become shallower. When the post-ageing temperature declines to $120^{\circ} \mathrm{C}$ (Fig. $2 \mathrm{~g}-\mathrm{i}$ ), the local corrosion behaviours of the two peak-aged samples (aged for $60 \mathrm{~h}$ and $120 \mathrm{~h}$, as shown in Fig. $2 \mathrm{~h}$ and i, respectively) are slighter than those of the samples peakaged at $180{ }^{\circ} \mathrm{C}$ and $150{ }^{\circ} \mathrm{C}$. Thus, the local corrosion 
resistance can be further improved after post-ageing at $120{ }^{\circ} \mathrm{C}$.

The correlation between measured values of the maximum corrosion depths and the yield strengths is shown in Fig. 3a. The combination of higher strength and corrosion resistance for the DA alloys (peak-aged at $180{ }^{\circ} \mathrm{C}, 150{ }^{\circ} \mathrm{C}$, and $120^{\circ} \mathrm{C}$ ), compared with those for the T6 and $\mathrm{T} 78$ alloys, is evident. The DA alloys peak-aged at $120{ }^{\circ} \mathrm{C}$ hold the most superior corrosion resistance (almost without IGC) and highest strength (50\% higher strength than that of the T6 peak-aged alloys) among the DA alloys subjected to the three post-ageing temperatures. In addition, the ductility of the DA alloys peak-aged at $120^{\circ} \mathrm{C}$ can be comparable to that of the T6 peak-aged alloys (Fig. 3b) [28, 29].

The unique corrosion behaviours of the DA samples revealed in this study indicate essential change in the microstructure. In order to explain the distinct corrosion behaviours, the microstructural features of the T6 peakaged sample (as shown in Fig. 4a, b) and the DA samples after post-ageing at $120{ }^{\circ} \mathrm{C}$ for $120 \mathrm{~h}$ (Fig. $\left.5 \mathrm{a}-\mathrm{d}\right), 150{ }^{\circ} \mathrm{C}$ for $8 \mathrm{~h}$ (Fig. 5e) and $180^{\circ} \mathrm{C}$ for $30 \mathrm{~min}$ (Fig. 5f) were examined in detail. After conventional T6 treatment, a number of nano-sized strengthening particles formed in the matrix (Fig. 4a). The needle-like (indicated by black arrows) and lath-like (indicated by white arrows) precipitates are recognized as $\beta^{\prime \prime}$ phase and $Q^{\prime \prime}$ phase, respectively $[34,35]$. Moreover, the grain boundary morphology is consisted of PFZ and GBS (Fig. 4b), which is believed to be responsible for the IGC susceptibility of the alloy (Fig. 1b) [4-6, 16, 17, 20].

Observing in the longitudinal plane (side-view), the DA sample after post-ageing at $120^{\circ} \mathrm{C}$ for $120 \mathrm{~h}$ possesses nano-lamellas which contain bundles of low-angle subgrain boundaries with nano-scale spacing typically between 50 and $200 \mathrm{~nm}$ (Fig. 5a). Figure 5b displays a sub-grain, viewed along the $[001]_{\mathrm{Al}}$ crystallographic axis, in the TEM sample prepared in the rolling plane (topview). Obviously, there are high-density dislocations distributed in the grain interior. Numerous lath-like nanosized precipitates (with a length of about $3 \mathrm{~nm}$ ), as indicated by white arrows, are uniformly distributed in the sample (Fig. 5c). These precipitates are identified as the $\mathrm{Q}^{\prime \prime}$-phase precipitates through the typical HRTEM image shown in Fig. 5d [28]. After post-peak-ageing at $150{ }^{\circ} \mathrm{C}$ for $8 \mathrm{~h}$, the average length (about $5 \mathrm{~nm}$ ) of the lath-like precipitates (indicated by white arrows) gets longer, as shown in Fig. 5e. Figure $5 \mathrm{f}$ shows the TEM image of the DA sample post-aged at $180{ }^{\circ} \mathrm{C}$ for $30 \mathrm{~min}$, and apparently the average length (about $10 \mathrm{~nm}$ ) of the precipitates (indicated by white arrows) increases further. Because of the remained dislocations and homogenously distributed finer nano-sized precipitates, the strength is higher and the ductility is better in the DA sample post-peak-aged at $120{ }^{\circ} \mathrm{C}$ compared to those in the samples post-peak-aged at $150{ }^{\circ} \mathrm{C}$ and $180{ }^{\circ} \mathrm{C}$.

Figure 6 shows the HAADF-STEM images and the corresponding $\mathrm{Al}, \mathrm{Mg}, \mathrm{Si}$ and $\mathrm{Cu}$ element mappings of the grain boundary precipitates in the T6 and DA samples. It can be seen that in the T6 peak-aged sample (Fig. 6a), there are some GBS simultaneously containing $\mathrm{Al}, \mathrm{Mg}, \mathrm{Si}$ and $\mathrm{Cu}$ elements, which can be identified as the Q-phase [36]. Q-phase and PFZ could form a corrosion microcouple [4-6], making the T6 samples being susceptible to IGC. There are also a few precipitates mainly containing $\mathrm{Mg}$ and Si elements, which should be $\beta$ phases [36]. The grain boundary $\beta$ phases could firstly dissolve as an effective anode because of the enrichment of $\mathrm{Mg}$ in them. As a result, some pitting would form along the grain boundaries. In the DA sample post-aged at $180{ }^{\circ} \mathrm{C}$ for $30 \mathrm{~min}$ (Fig. 6b), some GBS including $\mathrm{Cu}$ and $\mathrm{Mg}$ solute atoms, which can be identified as $S$ phases [37, 38], are discontinuously
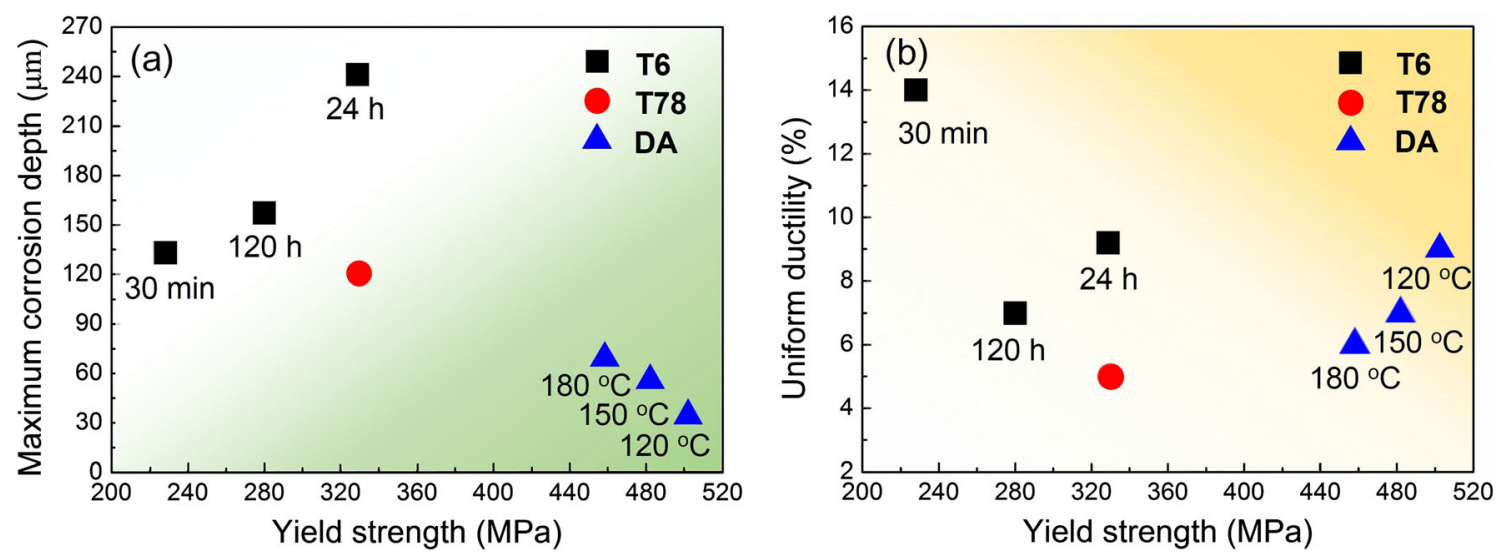

Fig. 3 a Combination of maximum corrosion depths and yield strength, $\mathbf{b}$ combination of uniform ductility and yield strength in samples treated with various conditions. All of the DA samples are peak-aged at different post-ageing temperatures as indicated in the images. The T78 results of the alloy were obtained in Ref. [22] 

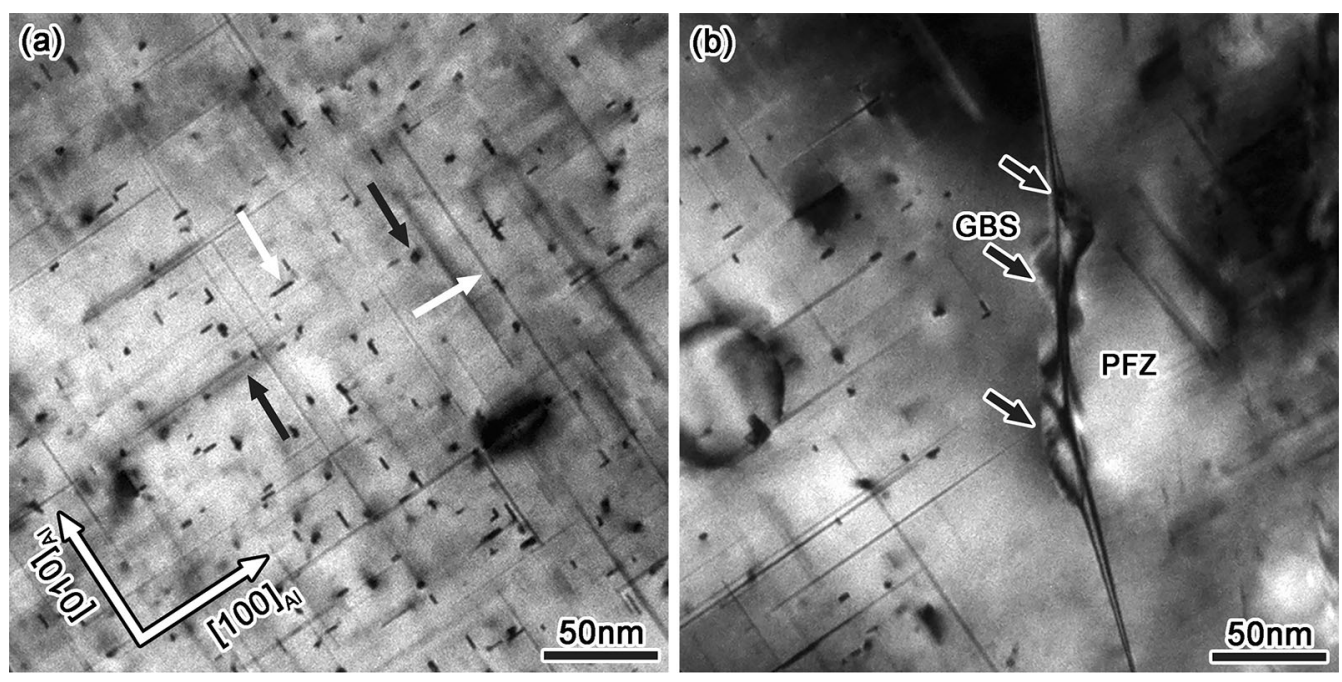

Fig. 4 TEM images of the T6 peak-aged samples: a matrix precipitates, $\mathbf{b}$ typical grain boundary feature
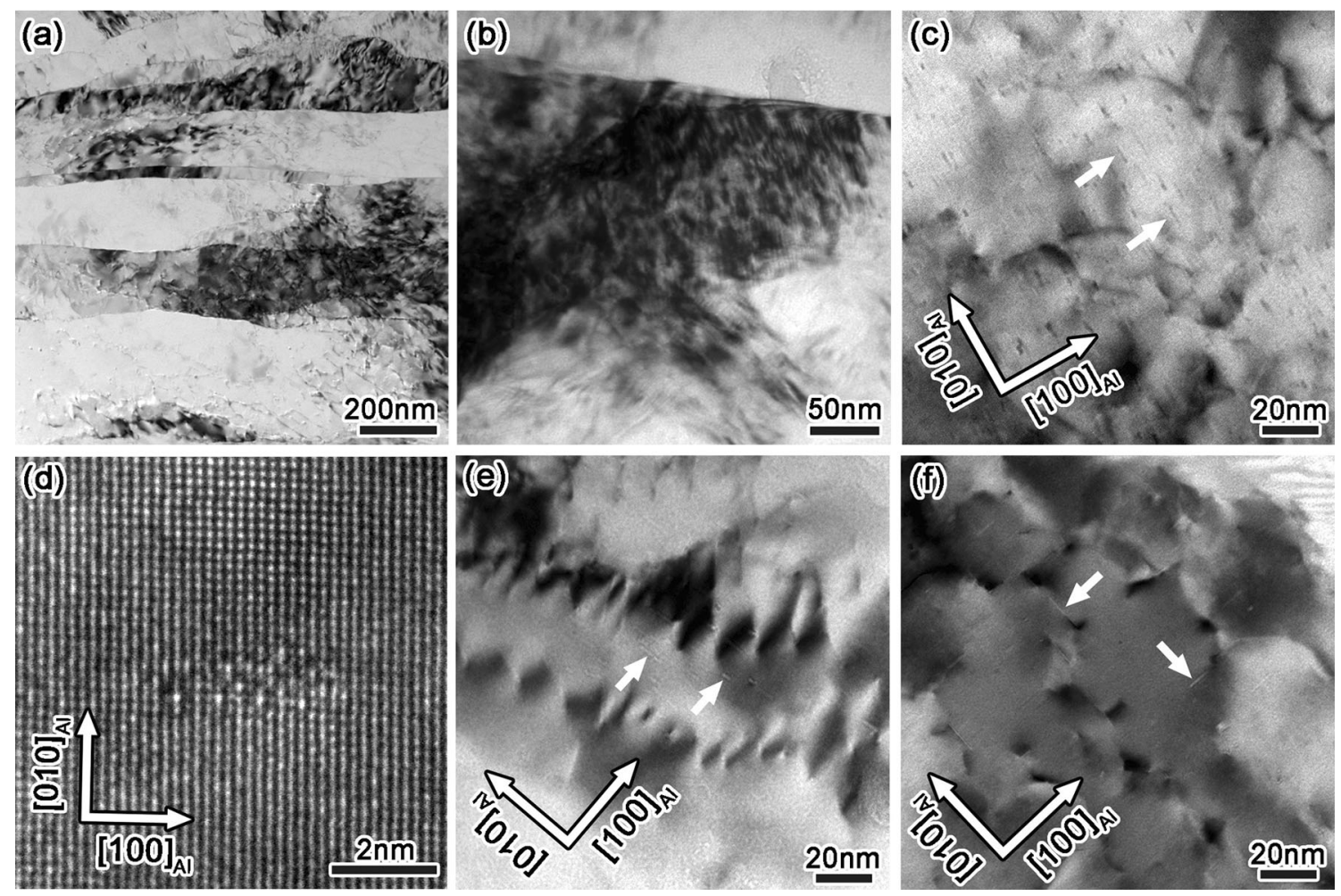

Fig. 5 TEM images of the DA samples post-aged a-d at $120{ }^{\circ} \mathrm{C}$ for $120 \mathrm{~h}$, e at $150{ }^{\circ} \mathrm{C}$ for $8 \mathrm{~h}, \mathbf{f}$ at $180{ }^{\circ} \mathrm{C}$ for 30 min recorded in a the side plane (side-view, the plane perpendicular to the transverse direction) and $\mathbf{b}-\mathbf{f}$ the rolling plane (plane-view). The white arrows in $\mathbf{c}, \mathbf{e}, \mathbf{f}$ indicate the nano-sized precipitates

distributed in the grain boundaries. Those phases could act as anodes firstly with the $\mathrm{Mg}$ atoms being corroded out, and then they could act as cathodes because of the remnant $\mathrm{S}$ phases being enriched of $\mathrm{Cu}$ elements [38, 39]. Because of the elongated lamellar grains [32] and the discontinuously distributed GBS in the grain boundaries, the corrosion paths would be interrupted, so that the corrosion depth is smaller than that in the T6 treated samples. However, in the DA samples post-aged at $150{ }^{\circ} \mathrm{C}$ for $8 \mathrm{~h}$ (Fig. 6c) and $120{ }^{\circ} \mathrm{C}$ for $120 \mathrm{~h}$ (Fig. $6 \mathrm{~d}$ ), little GBS are observed in the grain boundaries. Therefore, solute atoms segregate homogenously along the grain boundaries, which would remove the corrosion microcouples between the GBS and PFZ and decrease the local corrosion susceptibility of the 


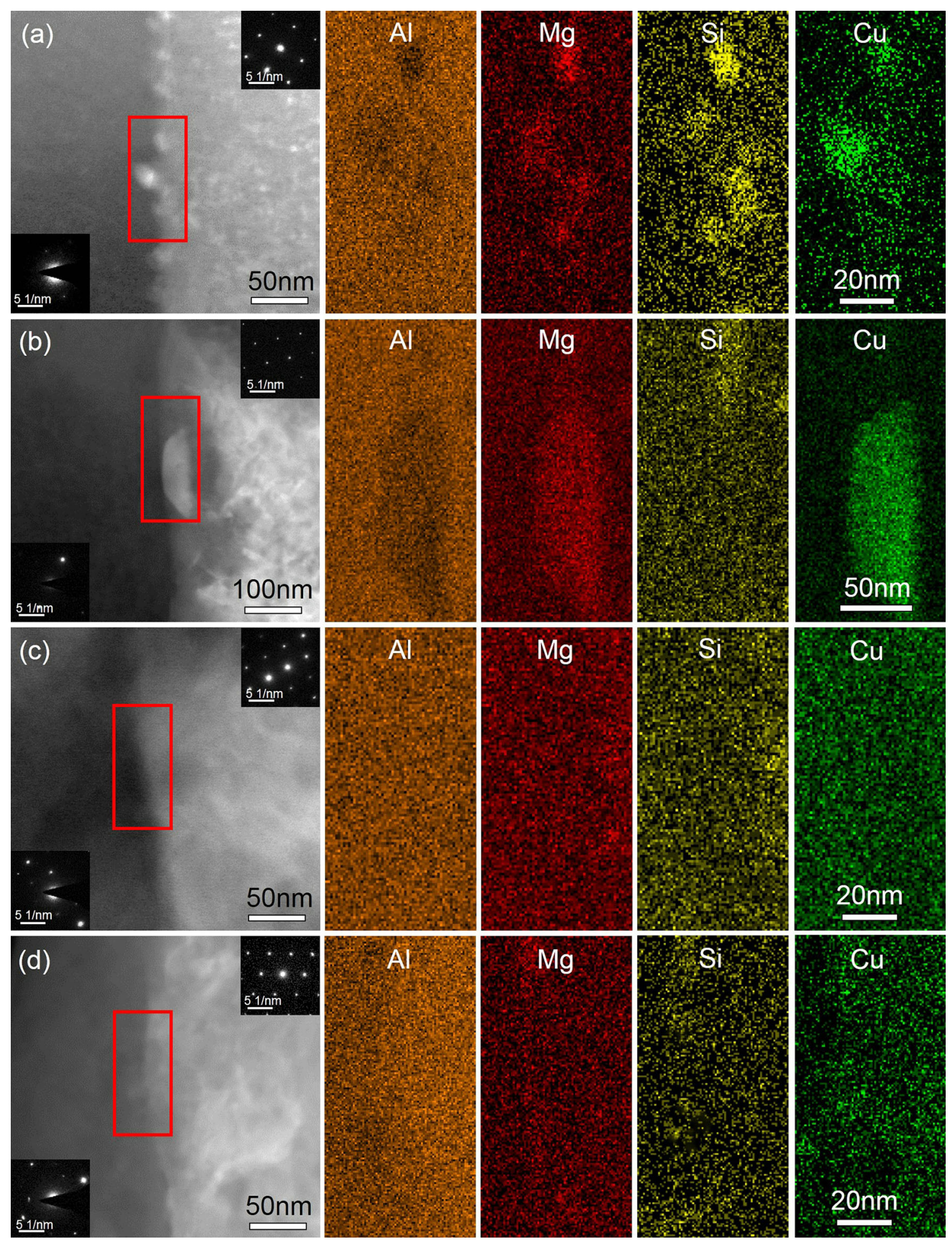

Fig. 6 HAADF-STEM images and the corresponding EDS mappings of the samples treated with different conditions: a T6 sample aged at $180{ }^{\circ} \mathrm{C}$ for $24 \mathrm{~h}, \mathbf{b}$ DA samples aged at $180{ }^{\circ} \mathrm{C}$ for $30 \mathrm{~min}, \mathbf{c}$ at $150{ }^{\circ} \mathrm{C}$ for $8 \mathrm{~h}, \mathbf{d}$ at $120{ }^{\circ} \mathrm{C}$ for $120 \mathrm{~h}$

alloys. It is worth noting that the maximum corrosion depth of the sample post-peak-aged at $120^{\circ} \mathrm{C}$ is lower than that of the sample post-peak-aged at $150{ }^{\circ} \mathrm{C}$. It is probably because that with a relatively higher temperature ageing treatment, solute atoms diffuse more easily to the grain boundaries, but it may still be hard to be observed by TEM.

The hierarchical nanostructures in the DA samples not only retain a high strength which is contributed from the 
nano-sized precipitates and crystal defects, such as nanoscale sub-grains and dislocations, but also show higher resistance to pitting corrosion and IGC. Apparently, these ubiquitous defects in the DA samples can act as preferential sites for the precipitations and reduce the tendency of the solutes diffusion towards grain boundaries to form GBS. As a result, the hierarchical nanostructures without GBS lead to a considerable prevention on the occurrence of IGC, closely related to the elongated lamellar grains and the removement of continuous microgalvanic couplings between PFZ and GBS [4-6, 16, 17, 19]. It is worth mentioning that the post-ageing temper for the DA sample is quite critical. If the post-ageing temperature is too low, it would induce less precipitates to strengthen the materials and less dislocations annihilation to improve the ductility [33]. While too high temperature ageing treatment, such as ageing at $180{ }^{\circ} \mathrm{C}$, would intensify solutes diffusion towards grain boundaries to form GBS, which would increase the IGC susceptibility of the alloy. In addition, higher temperature ageing would make solute atoms diffuse fast to form coarser precipitates, which would decrease the strength and ductility of the alloy.

\section{Conclusions}

In the present study, an optimized mechanical-thermal combinatorial process including pre-ageing, cold-rolling and post-ageing was proposed to enhance the local corrosion resistance in combination with good mechanical properties of an $\mathrm{Al}-\mathrm{Mg}-\mathrm{Si}-\mathrm{Cu}$ alloy. Based on the tensile tests, accelerated corrosion tests, SEM and TEM observations, the main conclusions are drawn as follows:

(1) Compared with conventional T6 temper, the mechanical-thermal combinatorial process leads to a transition in dominant corrosion mode from severe local corrosion, including pitting and IGC, to slight local corrosion. By optimizing the post-ageing temperature of combined deformation and ageing, high strength (502 MPa), good ductility (9\%) and excellent corrosion resistance can be achieved after post-peak-ageing at $120^{\circ} \mathrm{C}$.

(2) The tailored hierarchical nanostructures consisting of nano-precipitates, nano-lamellar sub-grains and dislocations achieved by the mechanical-thermal combinatorial process contribute to the high strength and good ductility.

(3) The homogenous distribution of solute atoms along the grain boundaries decreases the electrochemical difference between GBS and PFZ, resulting in the excellent corrosion resistance of the alloy processed by the mechanical-thermal combinatorial process.
Acknowledgements This work is supported by the National Key Research and Development Program of China (No. 2016YFB0300801) and the National Natural Science Foundation of China (Nos. 51471067, 11427806 and 51671082).

\section{References}

[1] J.C. Williams Jr., E.A. Starke, Acta Mater. 51, 5775 (2003)

[2] S.G. Pantelakis, N.D. Alexopoulos, Mater. Des. 29, 80 (2008)

[3] J.H. Chen, E. Costan, M.A. Van Huis, Q. Xu, H.W. Zandbergen, Science 312, 416 (2006)

[4] C. Vargel, in Corrosion of aluminum, ed. by S. David (Elsevier Ltd, Amsterdam, 2004), p. 81

[5] G. Svenningsen, J.E. Lein, A. Bjorgum, J.H. Nordlien, Y.D. Yu, K. Nisancioglu, Corros. Sci. 48, 226 (2006)

[6] G. Svenningsen, M.H. Larsen, J.H. Nordlien, K. Nisancioglu, Corros. Sci. 48, 258 (2006)

[7] I.J. Polmear, Mater. Forum 28, 1 (2004)

[8] X.K. Ji, H. Zhang, S. Luo, F.L. Jiang, D.F. Fu, Mater. Sci. Eng. A 649, 128 (2016)

[9] C. Liu, H. Zhang, F.L. Jiang, Trans. Nonferrous Met. Soc. China 24, 3477 (2014)

[10] W.L. Gao, H. Yan, C.H. Feng, Z. Lu, Trans. Nonferrous Met. Soc. China 24, 1206 (2014)

[11] Z. Gao, J.H. Chen, S.Y. Duan, X.B. Yang, C.L. Wu, Acta Metall. Sin. (Engl. Lett.) 29, 94 (2016)

[12] J.F. Li, Z.H. Ye, D.Y. Liu, Y.L. Chen, X.H. Zhang, X.Z. Xu, Z.Q. Zheng, Acta Metall. Sin. (Engl. Lett.) 30, 133 (2017)

[13] Y.L. Cheng, Z. Zhang, F.H. Cao, J.F. Li, J.Q. Zhang, J.M. Wang, C.N. Cao, Corros. Sci. 46, 1649 (2004)

[14] M. Tiryakioğlu, J.T. Staley, Physical metallurgy and the effect of alloying additions in aluminum alloys, in Handbook of Aluminum, ed. by G.E. Totten, D.S. Mackenzie (Springer, New York, 2003), p. 81

[15] L. Liu, J.H. Chen, S.B. Wang, C.H. Liu, S.S. Yang, C.L. Wu, Mater. Sci. Eng. A 606, 187 (2014)

[16] J.R. Zuo, L.G. Hou, J.T. Shi, H. Cui, L.Z. Zhuang, J.S. Zhang, J. Alloys Compd. 716, 220 (2017)

[17] D.M. Jiang, Y. Liu, S. Liang, W.L. Xie, J. Alloys Compd. 681, 57 (2016)

[18] X.Y. San, B. Zhang, B. Wu, X.X. Wei, E.E. Oguzie, X.L. Ma, Corros. Sci. 130, 143 (2018)

[19] M. Dixit, R.S. Mishra, K.K. Sankaran, Mater. Sci. Eng. A 478, 163 (2008)

[20] X.Y. Sun, B. Zhang, H.Q. Lin, Y. Zhou, L. Sun, J.Q. Wang, E.H. Han, W. Ke, Corros. Sci. 77, 103 (2013)

[21] R.N. Lumley, I.J. Polmear, A.G. Crosky, K. Hono, Acta Mater. $\mathbf{5 5}, 3015$ (2007)

[22] X.L. Li, J.H. Chen, C.H. Liu, J.N. Feng, S.H. Wang, Acta Metall. Sin. 49, 243 (2013). (in Chinese)

[23] L.P. Huang, K.H. Chen, S. Li, M. Song, Scr. Mater. 56, 305 (2007)

[24] K.D. Ralston, N. Birbilis, C.H.J. Davies, Scr. Mater. 63, 1201 (2010)

[25] J.G. Brunner, N. Birbilis, K.D. Ralston, S. Virtanen, Corros. Sci. 57, 209 (2012)

[26] K.D. Ralston, N. Birbilis, Corrosion 66, 075005-1 (2010)

[27] J.G. Brunner, N. Birbilis, K.D. Ralston, S. Virtanen, Corros. Sci. 57, 209 (2012)

[28] C.H. Liu, X.L. Li, S.H. Wang, J.H. Chen, Q. Teng, J. Chen, Y. Gu, Mater. Des. 54, 144 (2014)

[29] S.H. Wang, C.H. Liu, J.H. Chen, X.L. Li, D.H. Zhu, G.H. Tao, Mater. Sci. Eng. A 58, 233 (2013) 
[30] H. Li, Q.Z. Mao, Z.X. Wang, F.F. Miao, B.J. Fang, Z.Q. Zheng, Mater. Sci. Eng. A 617, 165 (2014)

[31] Z.X. Wang, H. Li, F.F. Miao, B.J. Fang, R.G. Song, Z.Q. Zheng, Mater. Sci. Eng. A 607, 313 (2014)

[32] Z.X. Wang, P. Chen, H. Li, B.J. Fang, R.G. Song, Z.Q. Zheng, Corros. Sci. 114, 156 (2017)

[33] C.H. Liu, Investigations of strengthening precipitate evolutions in high performance automotive aluminum alloys for tailoring their micro-structures and properties, Dissertation, Hunan University, 2015. (in Chinese)
[34] D.J. Chakrabarti, D.E. Laughlin, Prog. Mater Sci. 49, 389 (2004)

[35] J.H. Chen, C.H. Liu, China J. Nonferrous Met. 21, 2352 (2011)

[36] Y.F. Liao, J.H. Chen, C.H. Liu, X.L. Li, J.N. Feng, China J. Electron Micro. Soc. 31, 116 (2012)

[37] V. Radmilovic, R. Kilaas, U. Dahmen, G.J. Shiflet, Acta Mater. 47, 3987 (1999)

[38] J. Wang, B. Zhang, Y.T. Zhou, X.L. Ma, Acta Mater. 82, 22 (2015)

[39] J. Wang, B. Zhang, B. Wu, X.L. Ma, Corros. Sci. 105, 183 (2016) 